\title{
Advantages and Disadvantages of Using Information Communication Technologies in the Process of Forming Language Competence in Global Mining Education
}

\author{
Galina Chistyakova ${ }^{1}$, Evgeniya Bondareva $^{2}$, Ksenia Demidenko ${ }^{1, *}$, and Anastasia \\ Rolgayzer ${ }^{3}$ \\ ${ }^{1}$ Kemerovo State Medical University, 650029, 22a Voroshilova St., Kemerovo, Russia \\ ${ }^{2}$ Beijing University of Language and Culture, No.15 Xueyuan Road, Haidian District, Beijing \\ ${ }^{3}$ Kemerovo State University, 650000, 6 Krasnaya St., Kemerovo, Russia
}

\begin{abstract}
In connection with the COVID-19 pandemic, university education has undergone dramatic changes, resulting in a justified increase in the need for the development of distant learning. Today, information technology is an invaluable part of the learning process around the world. The purpose of this article is to analyze positive and negative aspects of applying information and communication technologies to the process of teaching foreign languages to students of mining specialties. The ways of solving the problems, identified in the discipline "Foreign language" in the course of the practical implementation of distance learning, are outlined. The possibilities of using such information tools as video lectures, video conferences, electronic coursebooks, computer testing are considered. Particular attention is devoted to the Moodle course management system as the most effective technology contributing to the formation of the language skills of future mining engineers. The authors come to the conclusion that each of the considered innovative educational technologies has a number of undeniable advantages, thus having a positive impact on both teachers and students. The recommendations developed by the authors provide a means for improving pedagogical design at the level of both individual teachers and universities.
\end{abstract}

\section{Introduction}

In time of digital globalization, morphing sociocultural paradigm, implementation of computer technologies in different spheres of human life and activity, as well as challenges of COVID-19 pandemic, specialists confront the problem of transforming traditional forms and methods of work in order to achieve their goals more efficiently. Education sector has also reacted to the process of almost complete digitalization. Gradually, various multimedia teaching aids, electronic educational platforms, online schools, online courses, etc. have come to existence. The training of mining engineers, which is conducted in technical

\footnotetext{
* Corresponding author: ksenan@mail.ru
} 
schools and universities around the world, has also responded to the use of digital technologies in teaching [1].

Much has been said about the benefits of multimedia learning resources. L. Kergel considers the online learning platform as a necessary part of the social policy of the state. He insists that at the present stage it is necessary to develop particular methods and didactic strategies for managing e-learning [2]. Numerous articles are devoted to reviewing and analyzing various e-learning platforms [3, 4]. Researching this topic, A.I. Awada \& I. Mocanu emphasize such undeniable advantages of using distance learning platforms as the possibility to combine various educational resources (coursebooks, tests, games, quizzes, etc.) into one training block, as well as the adaptability of the level of tests and quizzes to the level of students' knowledge of the topic, etc. Moreover, teachers can track the results and evaluate the progress of an individual student as well as of the whole group [4].

There is no doubt that introduction of digital education has greatly diversified educational process. Students obtained new opportunities for collecting and storing information. According to S. Islam and N. Jahan, spreading digital education through social networks has become one of the main trends in recent years. A survey conducted by the researchers has shown that using social media, such as Facebook, is considered to be an effective way of learning [5].

Particular attention should be paid to distance learning, which, along with offline forms of education, has a number of obvious advantages, the main of them being mastering the latest technical teaching aids by both teachers and students, developing students' independence and discipline, and selecting students' personal pace of studying. Moreover, applying a large number of interactive tasks offers the possibility of arousing and maintaining interest in the subject of study. The trend of gradual transformation of global mining education into the distant form seems to be rather understandable.

Teachers of foreign languages have long and effectively being using information and communication technologies, both in classroom activities and distance education. The most popular information and communication technologies are electronic coursebooks, online language practices, computer testing, online dictionaries, chats, podcasts, online educational programs available on video services like YouTube, digital libraries, etc.[6] Undoubtedly, each technology has a number of undeniable advantages. Therefore, the most advanced part of the language training staff has been actively involved with the aforementioned technologies in their professional activities for a considerable period of time.

However, full implementation of e-learning tools into training mine engineers became possible only in force majeure situation: the introduction of total distance learning caused by the COVID-19 pandemic. By doing so, many teachers have experienced significant difficulties due to the following reasons: firstly, average teacher's computer literacy is insufficient, and it poses a problem, since the implementation of most information and communication technology tools requires hard skills not lower than the "confident PC user" level; secondly, due to a wide variety of available technologies and insufficient experience in using e-learning resources, many teachers of higher educational institutions faced the problem of choosing information and communication technologies most appropriate for the educational process, which was difficult to solve.

\section{Materials and Methods}

It should be noted that when developing educational materials that contains information and communication technologies, it is necessary to take into consideration which educational major they are intended for. This article provides methodological advice for forming linguistic competence of future mining engineers. At the same time, we suggest that 
selecting specialized materials language teachers should try to solve several tasks simultaneously: teaching the training course material, as well as conducting current and final assessment of students' knowledge. Moreover, due to the mobility and compactness of materials created with the help of information and communication technologies, students have a potential to implement the professional topic glossaries, dialogue clichés, standard documents, etc. after fulfilling the training course and graduating educational institution. It became possible due to the compactness of the training materials.

Within the context of implementing distance learning technologies to training mine engineers, it is obvious that a competent combination of information communication technologies enables achieving the desired educational result as quickly and efficiently as possible. According to numerous scientific studies, the mixed form of education (the combination of the traditional in-class format with some elements of distance learning) is recognized to be the most effective one [7]. This position is supported by the fact that educational results in groups with mixed education forms are the highest as compared to the traditional one [8]. In the context of implementing distance learning technologies into the training of mining engineers, the process of educational design (specifically targeted planning of training courses) should be adjusted towards finding some learning forms and methods that can encourage students to self-study of foreign languages alongside with university training [9].

As the practice of the last few months has shown, the systemic implementation of the distance learning elements into the educational process has become a sort of a challenge for Russian higher educational institutions. Considerable changes in educational design were required in teaching individual disciplines as well as in implementing individual majors/specialties education programs. The experience gained during the COVID-19 distance learning period allows us to state that Russian system of higher educational institutions that train mining engineers, in general, have coped with the tasks set. However, there is a fairly large number of areas which are to be improved by both individual teachers and universities as institutions.

In the present research we intend to outline the ways of solving the problems that arose while implementing the information and communication technology based distance educational process for the discipline "Foreign language".

The recommendations developed by the authors of the article will help to improve the educational design both at the level of an individual teacher (teaching a foreign language to non-linguist specialists) and at the level of university training mining engineers as a whole (implementation of educational programs in one/several specialties).

Among the most effective electronic means of teaching foreign languages to mining engineers, which proved their worth during the COVID-19 pandemic distance learning period, one might mention video lectures, video conferences, electronic coursebooks, and computer testing. A tool that provides a means for aggregating the experience of sharing almost any electronic teaching aid is virtual learning environment, which is organically mounted into the electronic information educational environment of a university.

Video lectures (recorded lectures) have long proved to be an effective tool for communicating the necessary educational information to students [10]. With all the obvious advantages (for students: the possibility of multiple viewing, the availability for viewing at any time convenient, speeding up / slowing down / rewinding options, etc.; for teachers: no need to repeat the same material several times, saving speech efforts etc.) recording a video lecture requires from lecturers specific communication and representation skills which not all the teachers currently possess. Working on camera involves the ability of a lecturer to make eye contact with a virtual viewer through the camera lens, enrich the speech with emotions and gestures appropriate for this communication format, convey the information to virtual viewers in the form of a monologue. Recording a lecture also requires 
professional skills of a specialist, whose task is to provide all the technical aspects of video capture: the ability to frame the picture that the viewer will see (appearance of the speaker, background), liven up the view shot when mounting the lecture using a variety of angles, switching frames from the lecturer to the multimedia presentation, audio or video materials, etc. Recording high-quality video lectures requires additional efforts of university administration which must provide for the technical part of the activity (purchase equipment, prepare premises, hire employees for shooting and assembling lectures, etc.) and train faculty how to work in front of the camera.

At the same time video lectures should be assessed from the standpoint of not only technical characteristics, but also the form of presenting information on the discipline being taught. This should not be a traditional two-hour lecture, during which the teacher explains the material writing notes on the blackboard. Several 10-15-minute videos followed by a number of practice-oriented tasks for students to complete, will be perceived much more productively. These short videos, combined with the exercises to fulfil, become a sort of jigsaw puzzle pieces, which, when put together, enable students to build skills necessary at a particular stage of the educational process. This way of recording lectures on the discipline "Foreign Languages" turns out to be more effective when forming language skills of future mining engineers.

Videoconferences have become one of the most popular types of a sort of "live" communication of participants of distant learning process, carried out on the platforms of Zoom, Skype, DingTalk, etc. It is essential to use videoconferences as efficiently as possible in the context of shortage of time allotted for direct communication between teachers and students. Often, a videoconference is held as a traditional lecture, most part of which is devoted to a teacher communicating some educational information to students in a form of a monologue, and answering their questions in the end. Such ineffective use of time deprives students of the opportunity to receive advice and/or practice skills on topics of their interest in the discipline being mastered, which should be the most important goal of any videoconference.

In the course of teaching the "Foreign Language" discipline to mining engineers, it is most appropriate to solve the didactic task of explaining theoretical material (grammar rules, peculiarities of using new vocabulary, rules for writing paper projects, etc.) by means of video lectures. The teacher records the necessary material in advance and uploads it on the electronic educational platform, which all students have free access to at any convenient time. At the same time, students should be provided with some links to alternative sources of information on the topic under consideration (multimedia presentations, educational programs of YouTube channels, etc.), as well as exercises for practicing language skills (online language practices, computer testing, etc.). After studying theoretical material and fulfilling practical exercises independently, students must be given an opportunity to consult with the teacher on any unsolved problem. They should be able to do so during video conferences.

However, the most important task of any videoconference employed for implementing the "Foreign Language" discipline should be the development of speaking skills. Moreover, communication in a foreign language should take place in the form of an interactive conversation, involving students' communication with one another. Electronic platforms provide various tools for participants' group communication within a videoconference. For example, Zoom videoconferencing resource provides a means for dividing students into separate small groups within the Session Rooms in order to achieve the communication goals set for the lesson. Practice has shown that almost any communication technique aimed at developing speaking skills can be applied in a completely distant format, as well as in a mixed mode. 
«Role-play» is an example of learning and teaching technology which has proved to be most efficient for forming language skills. It offers the possibility of implementing foreign language training to the model of mining engineers' prospective work. In the course of this activity students learn how to deal with the possible challenges of their professional life. At the preparation stage (offline teamwork in the classroom) the teacher divides the group into several teams, presents the Role-play tasks, and establishes the level of students' creative freedom. The key positions (role distribution, staining of the game) and writing open-ended scenario are discussed distantly (online team work). Then the scenario is e-mailed to the teacher for reviewing. Presentation of the Role play to the teacher and the academic group is held offline (in-class team activity). Students have an additional opportunity to communicate in a foreign language at the stage of the discussion of the results (offline team activity) [9]. It should be noted that according to the surveys of interactive session participants, this type of activity is considered highly efficient, since it forms linguistic competence while saving time.

\section{Results and Discussion}

Modern platforms offer ample opportunities for interaction between teachers and students in the videoconference mode: hold an oral dialogue with other participants, receive and send messages, manage the meeting, display graphics, text and video elements, etc. The choice of an interactive platform determines the possibilities of interaction of a teacher and a student, as well as among students in a group. The teacher's competence is one of the major components of the activity. They should possess not only methodological, but also technical knowledge: the ability to use special software, applications, etc. Firstly, it requires teachers' putting extra efforts in developing their competencies. Secondly, higher educational institutions should provide all the necessary tools for recording video conferences: appropriate equipment, proper premises, software, regular training of teachers, as well as the availability of technical support staff. Moreover, everything described above should be provided systematically.

Electronic coursebooks have long become a part of the modern educational process as a tool that provides a means of accumulating several information communication technologies in one platform. Such a coursebook is at its core a multimedia space with hyperlinks for navigation all around the course. It also contains links to external resources. Video lectures, multimedia presentations, video and audio files, links to online dictionaries and electronic libraries, text blocks with theoretical information on the topics under consideration and practical tasks are successfully incorporated into the information block of a coursebook (theory and reference section). The training and assessment blocks involve, among other things, the use of online language practicies and computer testing. We believe that an electronic coursebook can also become an assistant in solving educational problems if there is an opportunity for a student to make notes and perform exercises in a personal copy of an electronic coursebook.

With all the obvious advantages of this tool, it must be recognized that it is more suitable for students' individual work. At the same time, for high-quality language training of mining engineers, it is necessary to have the possibility of verbal communication with other participants of the educational process. Moreover, an electronic coursebook is a fairly static educational resource, the development and further updating of which requires a significant amount of time. The material presented in electronic coursebooks needs to be updated regularly, especially links to external resources. Nevertheless, this cannot be done quickly, since electronic coursebooks are subjects to mandatory registration.

Computer testing is actively used for continuous assessment, progress check and finals. Tasks based on a high-quality task constructor have the following advantages: a diversity of 
exercises, a large number of questions that are aggregated randomly during each testing session according to the predetermined priorities, simplicity and clarity of processing results and displaying statistics, an objective approach to the process of testing of different groups of students. Fulfilling tests allows students to consolidate the covered material and identify existing knowledge lacks. Additionally, testing provides teachers with the possibility to assess the quality of the applied technologies and the curriculum as a whole.

One of the tools available for online testing of students is the Socrative free web application, which is compatible with all web browsers, as well as iOS and Android devices. Socrative allows teachers to create their own tests with automatic assessment, view test reports in real time and save the results in the teacher's personal account. Using this application, one can create various types of tests: tests containing one correct answer, multiple choice tests, open cloze tasks, true and false tasks, etc.

At the stage of starting a test, teachers can customize the way the results are presented to the group. Using tests with instant feedback allows students to independently monitor the correctness of fulfilling the tasks. Students can see their mistakes on the spot. Teachers can choose to add comments or explanations to each test question. Open navigation allows students to turn back to previous questions, change answers, and work at their own pace. The teacher paced option allows teachers to monitor and switch test questions in real time.

Despite the numerous advantages of this application, the following disadvantages can be highlighted:

- the system does not support uploading audio or video files, thereby excluding the possibility of using comprehension tasks to check understanding the content of the audio and video extracts;

- teachers cannot edit and comment students' answers;

- in case of unstable Internet connection during the test, the results will be lost.

Testing often looks like a purely mechanical assessment of knowledge (percentage of correct answers). In order to strengthen the educational component, it is recommended that teachers should add comments to incorrect answers explaining the material being mastered. This activity requires a much greater amount of teachers' work when making up tests.

In our opinion, the most effective tool providing a means of combining together almost any electronic learning tools is a virtual learning environment, which is organically built up into the electronic information and educational environment of universities. Moodle learning management system is considered to be one of the most popular virtual learning environments.

Moodle indisputably has a lot of advantages and provides many possibilities. Papers of many authors are devoted to the problem of using Moodle system in the educational process of universities $[11,12,13]$. It is noted that, despite its great potential, Moodle is mainly used as a source of storage of educational materials. However, students are aware of the importance of using other functions of this platform, such as News, Chats, Forums and Quizzes [11].

It is indisputable that Moodle has a lot of advantages and provides both students and teachers with many possibilities. Students effectively form and consolidate various communication and language skills with the help of this learning management system. While forming educational complex at their own discretion, teachers consider the duration of the course, its goals, the skills to be formed, and the level of students' knowledge. Within Moodle one can create and download all kinds of e-learning tutorials and set a particular sequence for studying and mastering the material. This system also has distinct advantages for students, as they can choose their own optimal pace of learning and performing tasks, thus mastering the offered material at a suitable time.

Using Moodle, foreign language teachers receive a wide range of tools. The system allows them to upload video lectures, recordings of webinars, audio and video applications, 
various podcasts, glossaries, provides the ability to insert hyperlinks to materials from Moodle and the Internet. Materials on professionally oriented topics, such as recordings of live monologues and dialogues, real documentation, etc. are of particular value.

Assessment materials can be uploaded into Moodle. The system allows teachers to set the number of attempts for a student to complete the task, to determine the timing for fulfilling tests, to leave comments upon both individual tasks and texts.

Such Moodle instrument as Forum allows students and teachers to discuss a variety of issues related to language acquisition and vocabulary development of any professional topic before the corresponding video conference or a traditional offline class is held. Communication is allowed only in a foreign language, which contributes to the improvement of the students' language competence.

\section{Conclusion}

Thus, information and communication technologies have proven to be highly efficient. Implementation of planned or emergent distant learning will not become a great challenge to the educational process, provided the basic information and communication technologies are mastered both by students and teachers.

Further work to improve information and communication technologies is required. The authors consider the following techniques to be the most productive in teaching foreign languages: video lectures, video conferences, electronic coursebooks, computer testing, and the use of Moodle learning management system. To fully benefit from these technologies teachers need to expand their professional horizons, critically assess the possibilities of the common traditional forms of work in comparison with modern ones based on the use of information and communication technologies. University management should provide teaching staff with training in using modern information and communication technologies and working in front of the camera, as well as increase the amount of funding allocated to the technical equipment of the educational process. In case of emergency, students who cannot provide themselves with technical means of education should be supplied with those. Besides, teachers' academic load should be redistributed by reducing the standard amount of classroom hours in favor of increasing the number of hours for the development of educational and methodological support using information and communication technologies.

\section{References}

1. S.A. Zhironkin, M.A. Tyulenev, O.V. Zhironkina, M. Hellmer, Metallurgical and Mining Industry 2 (2016)

2. L. Kergel, E-Learning and E-didactics: Learning in the digital age (Springer, New York, 2021)

3. M. Ouadoud, R. Nouha, C. Tarik, IJES, 9, 1 (2021)

4. I.A. Awada, I. Mocanu, INTED, 4, 1 (2021)

5. S. Islam, N. Jahan, IJCSIS, 16, 1 (2018)

6. M. Gluchmanova, Procedia-Social and Behavioral Sciences, 174 (2015)

7. E. Bondareva, G. Chistyakova, Yu. Kleshevskyi, S. Sergeev, A. Stepanov, E3S Web Conf. 21, 04019 (2017)

8. L.-T. Lee, J. Hung, Hum.-cen.Comp. Inf. Sci. 5, 13 (2015) 
9. G. Chistyakova, E. Bondareva, K. Demidenko, E. Podgornaya, O. Kadnikova, E3S Web Conf. 15, 04010 (2017)

10. C. Crook, L. Schofield, The Internet and Higher Education, 34, (2017)

11. C. Costa, H. Alvelos, L. Teixeira, Procedia Technology, 5 (2012)

12. T. Yu. Aikina, O. V. Sumtsova, D.I. Pavlov, International Journal of Emerging Technologies in Learning, 10, 3 (2015)

13. M.-D. Dascalu, S. Ruseti, M. Dascalu, D. S. Mc Namara, M. Carabas, T. Rebedea, S. Trausan-Matu, Computers in Human Behavior, 121, 106780 (2021) 